\title{
Effect of probiotics and xylo-oligosaccharide supplementation on nutrient digestibility, intestinal health and noxious gas emission in weanling pigs
}

\author{
J B Liu ${ }^{1,2, *}$, S C Cao ${ }^{1}$, J Liu', Y N Xie', and H F Zhang ${ }^{2}$
}

\begin{abstract}
* Corresponding Author: J B Liu
Tel: +86-0816-6089521, Fax: +86-0816-6089521

E-mail: liuswust@163.com
\end{abstract}

'School of Life Science and Engineering, Southwest University of Science and Technology, Mianyang 621010, China

${ }^{2}$ State Key Laboratory of Animal Nutrition, Institute of Animal Sciences, Chinese Academy of Agricultural Sciences, Beijing 100193, China

\section{ORCID}

J B Liu

https://orcid.org/0000-0001-5409-4426

SC Cao

https://orcid.org/0000-0001-9797-241X

J Liu

https://orcid.org/0000-0002-4245-863X

Y N Xie

https://orcid.org/0000-0003-4970-5311

H F Zhang

https://orcid.org/0000-0003-0177-8773

Submitted Dec 14, 2017; Revised Feb 1, 2018: Accepted Mar 13, 2018
Objective: This study was conducted to evaluate the effect of probiotics (Bacillus subtilis and Enterococcus faecium) and xylo-oligosaccharide (XOS) supplementation on growth performance, nutrient digestibility, serum profiles, intestinal health, fecal microbiota and noxious gas emission in weanling pigs.

Methods: A total of 240 weanling pigs ([Yorkshire $\times$ Landrace $] \times$ Duroc) with an average body weight (BW) of $6.3 \pm 0.15 \mathrm{~kg}$ were used in this 28 -day trial. Pigs were randomly allocated in 1 of the following 4 dietary treatments in a $2 \times 2$ factorial arrangement with 2 levels of probiotics ( 0 and $500 \mathrm{mg} / \mathrm{kg}$ probiotics) and XOS ( 0 and $200 \mathrm{mg} / \mathrm{kg}$ XOS) based on the BW and sex. Results: Administration of probiotics or XOS improved average daily gain $(\mathrm{p}<0.05)$ during 0 to $14 \mathrm{~d}$ and the overall period, while pigs that were treated with XOS had a greater average daily gain and feed efficiency $(\mathrm{p}<0.05)$ compared with unsupplemented treatments throughout 15 to $28 \mathrm{~d}$ and the whole experiment. Either probiotics or XOS treatments increased the apparent total tract digestibility of nutrients $(\mathrm{p}<0.05)$ during 0 to $14 \mathrm{~d}$. No effects on serum profiles were observed among treatments. The XOS increased villus height: crypt depth ratio in jejunum $(\mathrm{p}<0.05)$. The supplementation of probiotics $(500 \mathrm{mg} / \mathrm{kg})$ or XOS $(200 \mathrm{mg} / \mathrm{kg})$ alone improved the apparent total tract digestibility of dry matter, nitrogen and gross energy on $\mathrm{d} 14$, the activity of trypsin and decreased fecal NH3 concentration $(\mathrm{p}<0.05)$. Administration of XOS decreased fecal Escherichia coli counts ( $\mathrm{p}<0.05)$, while increased lactobacilli $(\mathrm{p}<0.05)$ on $\mathrm{d} 14$. There was no interaction between dietary supplementation of probiotics and XOS.

Conclusion: Inclusion of XOS at $200 \mathrm{mg} / \mathrm{kg}$ or probiotics (Bacillus subtilis and Enterococcus faecium) at $500 \mathrm{mg} / \mathrm{kg}$ in diets containing no antibiotics significantly improved the growth performance of weanling pigs. Once XOS is supplemented, further providing of probiotics is not needed since it exerts little additional effects.

Keywords: Probiotics; Xylo-oligosaccharide (XOS); Digestibility; Weanling Pigs; Growth Performance

\section{INTRODUCTION}

Due to the weaned stress syndrome in the piglet, associated with the reduction in feed intake, the inhibition of growth and the increase in diarrhea incidence after weaning, antibiotic growth promoters (AGP) were widely used in weanling pigs [1-3]. In recent years because of the worldwide trend to prohibit the use of AGP, much attention has been paid to developing alternatives to AGP for livestock.

Probiotics have been suggested as the most desirable alternative for livestock due to their beneficial effects $[4,5]$. It was reported that probiotics (Bacillus subtilis, $10^{6} \mathrm{cfu} / \mathrm{g}$ ) increased growth rate and feed efficiency in weanling pigs [6]. Recently, research has shown that Bacillus 
subtilis (B. subtilis, $10^{8} \mathrm{cfu} / \mathrm{g}$ ) had beneficial effects on growth performance in weanling pigs [7,8]. Enterococcus faecium ( $E$. faecium, $10^{6} \mathrm{cfu} / \mathrm{g}$ ) also improved growth performance and nutrient digestibility in weanling pigs [9].

Prebiotics have also been studied as a preferable alternative to AGP in many previous researches. Xylo-oligosaccharide (XOS) preferentially stimulates the growth or activity of advantageous bacteria such as bifidobacterium and other lactic acid bacteria in the gastrointestinal tract [10-12]. The inclusion of XOS in weanling pigs' diets may enhance immune function and improve the growth of the intestinal mucosa layer and intestinal microbiota diversity [13].

Both probiotics and prebiotics may also be considered as the alternatives to AGP. Several researches were conducted to study the effects of combining probiotics (Enterococus faecium or Lactobacillus) with prebiotics (mannan oligosaccharide, MOS) in poultry $[14,15]$, which indicate some positive effects. However, combining probiotics and XOS for weanling pigs, with expected complementary improvement of growth, has not yet been investigated. Therefore, the objective of this study was to determine the effect of probiotics and XOS supplementation on growth performance, nutrient digestibility, serum profiles, intestinal health, fecal microbiota and noxious gas emission in weanling pigs.

\section{MATERIALS AND METHODS}

\section{Sources of probiotics and XOS}

The probiotic preparation used in the current experiment was composed of a mixture of spray-dried spore forming B. subtilis endospores and $E$. faecium endospores, which is guaranteed to contain at least $1.4 \times 10^{11} \mathrm{cfu} / \mathrm{kg}$ of $B$. subtilis endospores and $1.4 \times 10^{9} \mathrm{cfu} / \mathrm{kg}$ of E. faecium endospores. The XOS (50\%) was produced by autohydrolysis of corn cobs and bagasse and spray-dried the the crude XOS-rich hydrolysates.

\section{Animals, housing, and treatments}

All animals received humane care as outlined in the Guide for the Care and Use of Experimental Animals (Southwest University of Science and Technology, Animal Care Committee).

A total of 240 pigs ([Landrace $\times$ Yorkshire $] \times$ Duroc, weaned at $21 \mathrm{~d}$ of age) with an average initial body weight (BW) of $6.3 \pm 0.15 \mathrm{~kg}$ were randomly assigned to 1 of 4 dietary treatments in a $2 \times 2$ factorial arrangement with 2 levels of probiotics $(0$ and $500 \mathrm{mg} / \mathrm{kg}$ probiotics) and XOS (0 and $200 \mathrm{mg} / \mathrm{kg}$ $\mathrm{XOS})$ based on the BW and sex. There were 6 replications (pens) per treatment and 10 pigs per pen ( 5 castrated males and 5 females). Probiotics or XOS was added at the expense of corn. The diets without antibiotics were formulated to provide all of the nutrients to meet or exceed NRC requirements (Table 1) [16]. The experiment lasted for $28 \mathrm{~d}$.

All of the pigs were housed in an environmentally controlled
Table 1. Diet composition (as-fed basis)

\begin{tabular}{lc}
\hline Items & CON \\
\hline Ingredients (\%) & \\
Corn & 54.86 \\
Extruded corn & 10.00 \\
Soybean meal (CP 46\%) & 25.00 \\
Fish meal (CP 65\%) & 3.00 \\
Soybean oil & 2.80 \\
Limestone & 0.65 \\
Dicalcium phosphate & 0.96 \\
NaCl & 0.35 \\
L-lys.HCl (78.8\%) & 0.36 \\
DL-methionine (99\%) & 0.08 \\
L-threonine (98.5\%) & 0.10 \\
L-tryptophan (10\%) & 0.23 \\
Choline chloride (50\%) & 0.10 \\
Phytase & 0.01 \\
Acidifier & 0.50 \\
Vitamin premix & \\
Trace mineral premix) & 0.50 \\
Analytical composition & 0.50 \\
DE (Mcal/kg) $)^{3)}$ & \\
CP (\%) & 3,400 \\
Lysine (\%) & 19.4 \\
Methionine (\%) & 1.42 \\
Ca (\%) & 0.40 \\
Total P (\%) & 0.68 \\
\hline CP. & 0.56 \\
\hline
\end{tabular}

$\mathrm{CP}$, crude protein; $\mathrm{DE}$, digestible energy.

1) Provided per kilograms of diet: $20,000 \mathrm{IU}$ of vitamin $A ; 4,000 \mathrm{IU}$ of vitamin $D_{3}$; $80 \mathrm{IU}$ of vitamin $\mathrm{E} ; 16 \mathrm{mg}$ of vitamin $\mathrm{K}_{3} ; 4 \mathrm{mg}$ of thiamine; $20 \mathrm{mg}$ of riboflavin; 6 $\mathrm{mg}$ of pyridoxine; $0.08 \mathrm{mg}$ of vitamin $B_{12} ; 120 \mathrm{mg}$ of niacin; $50 \mathrm{mg}$ of Ca-pantothenate; $2 \mathrm{mg}$ of folic acid and $0.08 \mathrm{mg}$ of biotin.

2) Provided per $\mathrm{kg}$ diet: $80 \mathrm{mg}$ of Fe; $140 \mathrm{mg}$ of $\mathrm{Cu} ; 179 \mathrm{mg}$ of $\mathrm{Zn} ; 12.5 \mathrm{mg}$ of $\mathrm{Mn}$; $0.5 \mathrm{mg}$ of $\mathrm{l} ; 0.25 \mathrm{mg}$ of $\mathrm{Co}$ and $0.4 \mathrm{mg}$ of Se.

${ }^{3)}$ Calculated values.

nursery facility with slatted plastic flooring and a mechanical ventilation system. The environmental temperature was maintained at $30^{\circ} \mathrm{C}$ for the first week of the experiment, and was then reduced by $1^{\circ} \mathrm{C}$ per week over the next three weeks. Each pen $(2 \times 2.5 \mathrm{~m})$ was provided with a stainless steel feeder and one nipple waterer, which allowed ad libitum access to feed and water throughout the experiment.

\section{Experimental procedures, sampling, and analysis}

Individual pig BW was measured initially and on d 14 and 28 of the experiment. Feed consumption per pen was also assessed on $\mathrm{d} 14$ and 28 of the experiment. The, average daily gain (ADG), average daily feed intake (ADFI), and gain-tofeed ratio (G:F) were also calculated.

During d 8-14 and 22-28, chromic oxide (0.2\%) was added to all the diets as an indigestible marker for the determination of apparent nutrient digestibility. On d 13-14 and the last 2 days of the experiment, fecal samples (at least $0.5 \mathrm{~kg}$ ) were collected from at least two pigs randomly from each pen via 
rectal massage, then pooled within the pens. All the feed and fecal samples were stored at $-20^{\circ} \mathrm{C}$ until further analysis. Concentrations of dry matter (DM) and $\mathrm{N}$ in the feed and feces were analyzed in accordance with AOAC procedures [17]. The DM of the feed and feces was determined after drying for 24 $\mathrm{h}$ at $103^{\circ} \mathrm{C}$. Chromium was analyzed via UV absorption spectrophotometry (Shimadzu, UV-1201, Kyoto, Japan) following the method described previously [18]. N content was determined by using a Kjeltec 2300 Analyzer (Foss Tecator AB, Hoeganaes, Sweden). The apparent total tract digestibility (ATTD) of DM and $\mathrm{N}$ was calculated using indirect-ratio methods. The gross energy (GE) in the feed and feces was determined using a calorimeter (Mode1241, Parr Instrument Co., Moline, IL, USA). The digestibility was calculated using the following formula: digestibility $(\%)=[1-(\mathbf{N f} \times \mathbf{C d}) /$ $(\mathbf{N d} \times \mathbf{C f})] \times 100$, where $\mathrm{Nf}$ is the nutrient concentration in feces (\% DM), $\mathrm{Nd}$ is the nutrient concentration in $\operatorname{diet}(\% \mathrm{DM})$, $\mathrm{Cd}$ is the chromium concentration in diet (\% DM), and Cf is the chromium concentration in feces (\% DM). Proximate analysis of diets for DM and ash was carried out according to AOAC [17]. Ash was determined after ignition of a weighed sample in a muffle furnace (Nabertherm, Bremen, Germany) at $550^{\circ} \mathrm{C}$ for $6 \mathrm{~h}$. The ash was then digested in aqua regia $\left(\mathrm{HCl} / \mathrm{HNO}_{3}\right.$ mixture), and the solution was used for Calcium (Ca) and phosphorus $(\mathrm{P})$ determination. Ca concentration was determined using an atomic absorption spectrophotometer (Varian'50, Varian, Palo Alto, CA, USA), and the concentration of $\mathrm{P}$ was determined spectrophotometrically (NanoDrop 2000c, Thermo Scientific, Wilmington, MA, USA) [19].

On $\mathrm{d} 28,4$ pigs ( 2 males and 2 females) reflecting average BW were randomly selected from each pen and blood samples were collected from the jugular vein into a sterile syringe and stored at $4^{\circ} \mathrm{C}$. Blood samples were then centrifuged at $3,000 \times \mathrm{g}$ for $15 \mathrm{~min}$ and serum was separated. The concentrations of glucose (GLU), total protein (TP), albumin (ALB), total cholesterol (TC), triglyceride (TG), and activities of alanine aminotransferase (ALT), aspartate aminotransferase (AST), and alkaline phosphatase (ALP) in the serum were measured with an automatic biochemical analyzer (Model 7020; Hitachi, Tokyo, Japan) using the assay kits (Shanghai Shensuo Youfu Medical Diagnostics Co. Ltd., Shanghai, China).

After blood samples, the representative pigs from each treatment ( 2 males and 2 female pigs per pen) reflecting average BW were selected and sacrificed by electrical stunning and exsanguination at the end of the experiment (day 28). The 3 segments of small intestine (approximately $2 \mathrm{~cm}$ from duodenum, jejunum, and ileum, respectively) were collected on $\mathrm{d} 28$ for determination of mucosal morphology. The segment approximately $15 \mathrm{~cm}$ distal to the pyloric junction was considered as the duodenum, that $55 \mathrm{~cm}$ distal to the pyloric junction was considered the jejunum, and a distal segment approximately $15 \mathrm{~cm}$ proximal to the ileocecal junction was considered the ileum $[20,21]$. The 3 segments from duodenum, jejunum and ileum, respectively, were cleaned with saline and then fixed in $10 \%$ neutral formalin. The fixed tissues were trimmed, embedded in paraffin for mucosal morphology and integrity. Intestinal morphological measurements included the following 3 indices: villus height (VH), crypt depth (CD) and $\mathrm{VH}: \mathrm{CD}$ ratio. These indexes were quantified as previously described [22]. Mean values of VH, CD, and their ratio within each segment were calculated.

Samples of mid-jejunum were also collected in $10 \%$ buffered neutral formaldehyde solution ( $\mathrm{pH} 7.2$ to 7.4 ) and stored for mucosal enzymes [3]. The activities of trypsin, pepsin, lipase, and amylase were determined using ELISA method (Nanjin Jiancheng Biotechnology Co. Ltd., Nanjin, China) as previously described [23].

On d 14 and 28 of the experiment, fecal samples were collected by rectal massage from all pigs from each pen, then pooled, and transported to the lab for immediate analysis. One gram of the composite fecal sample from each pen was diluted with $9 \mathrm{~mL}$ of $1 \%$ peptone broth (Becton, Dickinson and Co., Franklin Lakes, NJ, USA), and then homogenized. Viable counts of bacteria in fecal samples were then conducted by plating serial 10 -fold dilutions (in $1 \%$ peptone solution) onto MacConkey agar plates and Lactobacillus spp. medium III agar plates to isolate the Escherichia coli (E. coli) and lactobacilli, respectively. The lactobacilli medium III agar plates were then incubated for $48 \mathrm{~h}$ at $39^{\circ} \mathrm{C}$ under anaerobic conditions. MacConkey agar plates were incubated for $24 \mathrm{~h}$ at $37^{\circ} \mathrm{C}$. E. coli and lactobacilli colonies were counted immediately after removal from the incubator.

At the end of the experiment, fresh fecal samples (300 g) were collected randomly from at least 2 pigs in each pen every afternoon. Then these samples were stored in $2.6-\mathrm{L}$ sealed plastic boxes in duplicate and fermented for $48 \mathrm{~h}$ at $32^{\circ} \mathrm{C}$. Fecal $\mathrm{NH}_{3}$ and $\mathrm{H}_{2} \mathrm{~S}$ concentrations were determined as previously described [9]. After the fermentation period, the plastic boxes were punctured and headspace air was sampled approximately $2.0 \mathrm{~cm}$ above the samples at a rate of $100 \mathrm{~mL} / \mathrm{min}$ using a Gastec detector (GV-100S; Gastec Corp., Kanagawa, Japan). Concentrations of $\mathrm{NH}_{3}$ and $\mathrm{H}_{2} \mathrm{~S}$ were measured within the scope of 5 to100 ppm (No.3La, detector tube; Gastec Corp., Japan) and 2 to 20 ppm (No.4LL, detector tube; Gastec Corp., Japan).

\section{Statistical analysis}

All data were analyzed by analysis of variance (SAS, Cary, NC, USA) using a $2 \times 2$ factorial arrangement of treatments with the pen being considered as the experimental unit [24]. The model utilized included the effects of probiotics and XOS, as well as the interaction. When a significant interaction was observed, the means of each treatment were compared using 
Fisher's protected least significant difference. Variability in the data is expressed as the standard error means and a probability level of $p<0.05$ was considered to be statistically significant.

\section{RESULTS}

\section{Growth performance}

The dietary probiotics or XOS supplementation alone increased ADG $(\mathrm{p}<0.05)$ during $\mathrm{d} 0-14$, while no effect was observed for ADFI or G:F ( $p>0.05$; Table 2). During d 15-28, inclusion of XOS improved ADG and G/F ( $\mathrm{p}<0.05)$. In the whole experiment, the administration of probiotics increased ADG by $12 \%(\mathrm{p}<0.05)$, while XOS improved ADG by $17 \%$ and $\mathrm{G} / \mathrm{F}$ by $14 \%(\mathrm{p}<0.05)$. No interaction between probiotics and XOS on growth performance was detected $(p>0.05)$ throughout the experiment.

\section{Nutrient digestibility}

On $\mathrm{d} 14$, the ATTD of DM, N, and GE was increased $(\mathrm{p}<0.05)$ by either probiotics or XOS supplementation (Table 3). On d 28 , the dietary treatments did not affect the ATTD of DM, N, ether extract, crude fiber, or GE ( $\mathrm{p}>0.05$ ). There was no interaction between probiotics and XOS on nutrient digestibility ( $>0.05)$ in the whole experiment.

\section{Serum profiles}

Serum ALT, AST, TP, ALB, ALP, GLU, TG, or TC was not affected by the dietary treatments ( $\mathrm{p}>0.05$; Table 4 ). No interaction between probiotics and XOS on serum profiles was detected $(p>0.05)$ throughout the experiment.

Table 2. Effects of probiotics and XOS on growth performance in weanling pigs ${ }^{11}$

\begin{tabular}{|c|c|c|c|c|c|c|c|c|}
\hline \multirow{2}{*}{ Items } & \multicolumn{2}{|c|}{-Probiotics } & \multicolumn{2}{|c|}{ +Probiotics } & \multirow{2}{*}{ SEM } & \multicolumn{3}{|c|}{$p$-value ${ }^{2)}$} \\
\hline & $-\mathrm{XOS}$ & $+\mathrm{XOS}$ & $-\mathrm{XOS}$ & $+\mathrm{XOS}$ & & Probiotics & $\mathrm{xOS}$ & Probiotics $\times \mathrm{XOS}$ \\
\hline \multicolumn{9}{|l|}{ d 0-14 } \\
\hline ADG (g) & 238 & 271 & 269 & 300 & 12 & 0.04 & 0.03 & 0.90 \\
\hline $\operatorname{ADFI}(g)$ & 308 & 334 & 325 & 351 & 22 & 0.18 & 0.13 & 0.97 \\
\hline $\mathrm{G} / \mathrm{F}$ & 0.773 & 0.811 & 0.828 & 0.855 & 0.026 & 0.16 & 0.44 & 0.88 \\
\hline \multicolumn{9}{|l|}{ d $15-28$} \\
\hline ADG $(\mathrm{g})$ & 436 & 516 & 489 & 512 & 21 & 0.21 & 0.02 & 0.13 \\
\hline ADFI (g) & 740 & 737 & 776 & 783 & 38 & 0.32 & 0.83 & 0.71 \\
\hline $\mathrm{G} / \mathrm{F}$ & 0.589 & 0.700 & 0.630 & 0.654 & 0.017 & 0.85 & 0.03 & 0.17 \\
\hline \multicolumn{9}{|l|}{$\mathrm{d} 0-28$} \\
\hline ADG (g) & 337 & 393 & 379 & 406 & 18 & 0.03 & 0.03 & 0.21 \\
\hline ADFI (g) & 524 & 535 & 551 & 567 & 33 & 0.24 & 0.23 & 0.83 \\
\hline $\mathrm{G} / \mathrm{F}$ & 0.643 & 0.735 & 0.688 & 0.716 & 0.019 & 0.58 & 0.02 & 0.24 \\
\hline
\end{tabular}

XOS, xylo-oligosaccharide; SEM, pooled standard error of the means; $A D G$, average daily gain; ADFI, average daily feed intake; G/F, gain-to-feed ratio.

${ }^{1)} A D G$ mean represents 6 pens ( $n=6 /$ group) and feed consumption mean represents 6 pens ( $n=6 /$ group).

2) Probiotics, probiotics effect; $X O S$, XOS effect; Probiotics $\times X O S$, interaction between probiotics and XOS.

Table 3. Effects of probiotics and XOS on nutrient digestibility in weanling pigs ${ }^{11}$

\begin{tabular}{|c|c|c|c|c|c|c|c|c|}
\hline \multirow{2}{*}{ Items (\%) } & \multicolumn{2}{|c|}{-Probiotics } & \multicolumn{2}{|c|}{ +Probiotics } & \multirow{2}{*}{ SEM } & \multicolumn{3}{|c|}{$p$-value ${ }^{2)}$} \\
\hline & $-\mathrm{XOS}$ & $+\mathrm{XOS}$ & $-\mathrm{XOS}$ & $+\mathrm{XOS}$ & & Probiotics & XOS & Probiotics $\times \mathrm{XOS}$ \\
\hline \multicolumn{9}{|l|}{ d 14} \\
\hline$N$ & 78.9 & 80.6 & 80.8 & 82.7 & 0.1 & 0.01 & 0.01 & 0.85 \\
\hline EE & 64.5 & 65.7 & 67.4 & 66.1 & 0.3 & 0.20 & 0.11 & 0.43 \\
\hline $\mathrm{CF}$ & 52.4 & 53.6 & 53.1 & 54.2 & 0.4 & 0.18 & 0.19 & 0.25 \\
\hline \multicolumn{9}{|l|}{$\mathrm{d} 28$} \\
\hline DM & 78.7 & 80.2 & 79.6 & 80.0 & 0.3 & 0.63 & 0.17 & 0.41 \\
\hline N & 79.8 & 82.1 & 79.7 & 80.4 & 0.3 & 0.15 & 0.11 & 0.17 \\
\hline EE & 66.6 & 67.4 & 66.8 & 67.9 & 0.5 & 0.28 & 0.33 & 0.21 \\
\hline $\mathrm{CF}$ & 53.4 & 54.1 & 52.8 & 54.8 & 0.7 & 0.43 & 0.25 & 0.44 \\
\hline
\end{tabular}

XOS, xylo-oligosaccharide; SEM, pooled standard error of the means; DM, dry matter; N, nitrogen; EE, ether extract; CF, crude fiber; GE, gross energy.

1) Each mean represents 6 pens ( $n=6 /$ group).

2) Probiotics, probiotics effect; XOS, XOS effect; Probiotics $\times$ XOS, interaction between probiotics and XOS. 
Table 4. Effects of probiotics and XOS on serum profiles in weanling pigs ${ }^{1)}$

\begin{tabular}{|c|c|c|c|c|c|c|c|c|}
\hline \multirow{2}{*}{ Items } & \multicolumn{2}{|c|}{-Probiotics } & \multicolumn{2}{|c|}{ +Probiotics } & \multirow{2}{*}{ SEM } & \multicolumn{3}{|c|}{$p$-value ${ }^{2)}$} \\
\hline & -XOS & $+\mathrm{XOS}$ & -XOS & $+\mathrm{XOS}$ & & Probiotics & XOS & Probiotics $\times \mathrm{XOS}$ \\
\hline AlT (U/L) & 86.4 & 78.5 & 85.4 & 83.1 & 4.1 & 0.20 & 0.12 & 0.12 \\
\hline AST (U/L) & 74.9 & 76.0 & 77.8 & 82.1 & 3.9 & 0.11 & 0.33 & 0.24 \\
\hline $\mathrm{TP}(\mathrm{g} / \mathrm{L})$ & 59.2 & 59.3 & 61.7 & 59.5 & 3.0 & 0.32 & 0.22 & 0.48 \\
\hline$A L B(g / L)$ & 34.2 & 33.3 & 35.5 & 35.3 & 2.2 & 0.40 & 0.25 & 0.53 \\
\hline$A L P(U / L)$ & 354.5 & 384.0 & 381.0 & 349.1 & 19.1 & 0.21 & 0.15 & 0.12 \\
\hline $\mathrm{GLU}(\mathrm{mmol} / \mathrm{L})$ & 5.7 & 5.7 & 5.5 & 5.4 & 0.9 & 0.33 & 0.60 & 0.27 \\
\hline $\mathrm{TG}(\mathrm{mmol} / \mathrm{L})$ & 0.8 & 0.7 & 0.7 & 1.0 & 0.02 & 0.11 & 0.13 & 0.10 \\
\hline $\mathrm{TC}(\mathrm{mmol} / \mathrm{L})$ & 2.4 & 2.3 & 2.4 & 2.7 & 0.10 & 0.41 & 0.54 & 0.29 \\
\hline
\end{tabular}

XOS, xylo-oligosaccharide; SEM, pooled standard error of the means; ALT, alanine aminotransferase; AST, aspartate aminotransferase; TP, total protein; ALB, albumin; ALP, alkaline phosphatase; GLU, glucose; TG, total cholesterol; TC, triglyceride.

1) Each mean represents 6 pens $(n=6 /$ group).

2) Probiotics, probiotics effect; $X O S, X O S$ effect; Probiotics $\times X O S$, interaction between probiotics and XOS.

\section{Intestinal morphology}

There was no difference ( $\mathrm{p}>0.05)$ in $\mathrm{VH}, \mathrm{CD}$, or $\mathrm{VH}: \mathrm{CD}$ ratio of duodenum and ileum (Table 5). The XOS increased VH:CD ratio in jejunum $(\mathrm{p}<0.05)$, but did not influence $\mathrm{VH}, \mathrm{CD}$ ( $\mathrm{p}>$ 0.05 ). There was no interaction between probiotics and XOS on intestinal morphology $(\mathrm{p}>0.05)$ in the whole experiment.
Jejunum mucosal enzyme activities

Administration of either probiotics or XOS increased the activity of trypsin $(\mathrm{p}<0.05)$, while amylase activity was increased $(\mathrm{p}<0.05)$ by XOS supplementation (Table 6$)$. No treatment effect was observed in the activity of pepsin or lipase $(p>0.05)$. No interaction between probiotics and XOS on jejunum mucosal enzyme activities was detected $(\mathrm{p}>0.05)$ throughout the

Table 5. Effects of probiotics and XOS on intestinal morphology in weanling pigs ${ }^{1)}$

\begin{tabular}{|c|c|c|c|c|c|c|c|c|}
\hline \multirow{2}{*}{ Items } & \multicolumn{2}{|c|}{-Probiotics } & \multicolumn{2}{|c|}{ +Probiotics } & \multirow{2}{*}{ SEM } & \multicolumn{3}{|c|}{$p$-value ${ }^{2)}$} \\
\hline & $-\mathrm{XOS}$ & $+\mathrm{XOS}$ & $-\mathrm{XOS}$ & $+\mathrm{XOS}$ & & Probiotics & $\mathrm{xOS}$ & Probiotics $\times \mathrm{XOS}$ \\
\hline \multicolumn{9}{|l|}{ Duodenum } \\
\hline$C D(\mu m)$ & 310 & 300 & 326 & 297 & 29 & 0.65 & 0.14 & 0.23 \\
\hline $\mathrm{VH}: \mathrm{CD}$ & 1.05 & 1.17 & 1.03 & 1.22 & 0.04 & 0.30 & 0.55 & 0.73 \\
\hline \multicolumn{9}{|l|}{ Jejunum } \\
\hline $\mathrm{CD}(\mu \mathrm{m})$ & 286 & 267 & 269 & 280 & 14 & 0.14 & 0.26 & 0.38 \\
\hline $\mathrm{VH}: \mathrm{CD}$ & 1.15 & 1.28 & 1.18 & 1.31 & 0.05 & 0.46 & 0.03 & 0.11 \\
\hline \multicolumn{9}{|l|}{ Ileum } \\
\hline $\mathrm{VH}(\mu \mathrm{m})$ & 300 & 302 & 282 & 315 & 28 & 0.24 & 0.29 & 0.42 \\
\hline$C D(\mu \mathrm{m})$ & 254 & 241 & 232 & 231 & 20 & 0.69 & 0.30 & 0.38 \\
\hline
\end{tabular}

XOS, xylo-oligosaccharide; SEM, pooled standard error of the means; VH, villus height; $C D$, crypt depth.

${ }^{1)}$ Each mean represents 6 pens ( $n=6 /$ group).

2) Probiotics, probiotics effect; XOS, XOS effect; Probiotics $\times$ XOS, interaction between probiotics and XOS.

Table 6. Effects of probiotics and XOS on jejunum mucosal enzyme activities in weanling pigs ${ }^{1)}$

\begin{tabular}{|c|c|c|c|c|c|c|c|c|}
\hline \multirow{2}{*}{ Items } & \multicolumn{2}{|c|}{-Probiotics } & \multicolumn{2}{|c|}{ +Probiotics } & \multirow{2}{*}{ SEM } & \multicolumn{3}{|c|}{ p-value ${ }^{2)}$} \\
\hline & -XOS & $+\mathrm{XOS}$ & $-\mathrm{XOS}$ & $+\mathrm{XOS}$ & & Probiotics & XOS & Probiotics $\times \mathrm{XOS}$ \\
\hline Trypsin (U/mg prot) & 1,595 & 1,796 & 1,650 & 1,784 & 20.4 & 0.04 & 0.03 & 0.15 \\
\hline Pepsin (U/mg prot) & 27.06 & 22.14 & 26.61 & 25.80 & 1.53 & 0.31 & 0.13 & 0.65 \\
\hline Lipase (U/mg prot) & 83.87 & 84.87 & 85.36 & 86.39 & 3.33 & 0.39 & 0.20 & 0.42 \\
\hline Amylase (U/mg prot) & 167.9 & 211.5 & 177.3 & 214.0 & 7.28 & 0.36 & 0.04 & 0.33 \\
\hline
\end{tabular}

XOS, xylo-oligosaccharide; SEM, pooled standard error of the means.

1) Each mean represents 6 pens ( $n=6 /$ group).

2) Probiotics, probiotics effect; XOS, XOS effect; Probiotics $\times$ XOS, interaction between probiotics and XOS. 
experiment.

\section{Fecal microbiota}

On d 14, fecal microbial shedding of lactobacilli was increased in XOS treatment compared with pigs fed any other diets $(\mathrm{p}<$ 0.05 , Table 7). Fecal E. coli counts were decreased by XOS administration $(\mathrm{p}<0.05)$. However, fecal microbial shedding was not affected by dietary treatments $(\mathrm{p}>0.05)$ on $\mathrm{d} 28$.

\section{Noxious gas contents}

Fecal $\mathrm{NH}_{3}$ levels were reduced by either probiotics or XOS $(\mathrm{p}<$ 0.05 ), whereas $\mathrm{H}_{2} \mathrm{~S}$ did not differ ( $>0.05$; Table 8 ). No interaction between probiotics and XOS on noxious gas contents was detected $(\mathrm{p}>0.05)$.

\section{DISCUSSION}

Probiotics of B. subtilis $\left(1 \times 10^{11} \mathrm{cfu} / \mathrm{kg}\right)$ and E. faecium $\left(1 \times 10^{9}\right.$ $\mathrm{cfu} / \mathrm{kg}$ ) are widely used in weanling pigs [7-9], which can exert beneficial effects on growth performance, intestinal morphology, immunity and several serum profiles. Increased ADG of weanling pigs fed diets supplemented with probiotics (500 $\mathrm{mg} / \mathrm{kg}$ ) containing $1.4 \times 10^{11} \mathrm{cfu} / \mathrm{kg}$ of B. subtilis and $1.4 \times 10^{9}$ $\mathrm{cfu} / \mathrm{kg}$ of E. faecium observed in the current study was consistent with data reported by a previous study, which observed improved ADG and ADFI in weanling pigs fed diets with 3 $\mathrm{g} / \mathrm{kg}$ B. subtilis $\left(1.4 \times 10^{11} \mathrm{cfu} / \mathrm{kg}\right)$ [7]. Moreover, several studies also identified the positive effects of $B$. subtilis on growth performance in weanling pigs $[25,26]$. The greater ADG may be due to higher ADFI and G:F in previous studies [7,27]. $E$. faecium $\left(1 \times 10^{9} \mathrm{cfu} / \mathrm{kg}\right)$ led to an increase in ADG and G:F in weanling pigs [9]. Previous studies also indicated that dietary E. faecium supplementation could exert better positive effects on ADG and G:F in nursery pigs [28-30]. However, some studies failed to observe the positive effect on growth performance in response to probiotics. For example, a study indicated that there was no effect on the growth performance when $10^{12}$ cfu/kg B. subtilis supplementation was added to weanling pigs' diets [31]. In addition, another study observed no effects of E. faecium $\left(1.4 \times 10^{9} \mathrm{cfu} / \mathrm{kg}\right)$ on growth performance in weanling pigs [32]. In this study, dietary copper level was 140 ppm, which can be considered as a pharmacological level and could exert an anti-bacterial property. This property might affect probiotics because they are live bacteria. It is well documented that the inconsistent results may be due to the variation in species composition and viability of probiotic products, supplementation level, diet composition, animal age, health status, hygiene and environmental factors [7]. However, dietary probiotics may exert better positive effects in nursery pigs than in growing-finishing pigs because the digestive system, immunity, and capacity to resist intestinal disorders develop as pigs become older [33]. Similarly, previous studies suggest that growth performance of growing-finishing pigs may remain unchanged under probiotics feeding treatment [34]. There was no effect on the growth performance of growing-finishing pigs fed B. subtilis diets [35]. A vitro study also indicated that XOS can stimulate greater bifidobacteria levels compared with other oligosaccharides [36]. Recently, research has shown that XOS (100 mg/kg or $75 \mathrm{mg} / \mathrm{kg}$ ) can improve growth performance and strengthen humoral immunity in broilers

Table 7. Effects of probiotics and XOS on fecal microbiota in weanling pigs ${ }^{1)}$

\begin{tabular}{|c|c|c|c|c|c|c|c|c|}
\hline \multirow{2}{*}{ Items } & \multicolumn{2}{|c|}{-Probiotics } & \multicolumn{2}{|c|}{ +Probiotics } & \multirow{2}{*}{ SEM } & \multicolumn{3}{|c|}{$p$-value ${ }^{2)}$} \\
\hline & $-\mathrm{XOS}$ & $+\mathrm{XOS}$ & $-\mathrm{XOS}$ & $+\mathrm{XOS}$ & & Probiotics & $\mathrm{xOS}$ & Probiotics $\times$ XOS \\
\hline \multicolumn{9}{|c|}{ Lactobacilli $\left(\log ^{10} \mathrm{cfu} / \mathrm{g}\right)$} \\
\hline d 14 & 7.3 & 7.6 & 7.3 & 7.9 & 0.1 & 0.12 & 0.04 & 0.11 \\
\hline $\mathrm{d} 28$ & 7.2 & 7.4 & 7.3 & 7.5 & 0.1 & 0.83 & 0.33 & 0.80 \\
\hline \multicolumn{9}{|c|}{ Escherichia coli $\left(\log ^{10} \mathrm{cfu} / \mathrm{g}\right)$} \\
\hline d 14 & 6.3 & 6.0 & 6.4 & 6.0 & 0.1 & 0.31 & 0.02 & 0.49 \\
\hline $\mathrm{d} 28$ & 6.2 & 6.1 & 6.0 & 6.1 & 0.1 & 0.66 & 0.53 & 0.78 \\
\hline
\end{tabular}

XOS, xylo-oligosaccharide; SEM, pooled standard error of the means.

${ }^{1)}$ Each mean represents 6 pens ( $n=6 /$ group).

2) Probiotics, probiotics effect; $X O S$, XOS effect; Probiotics $\times X O S$, interaction between probiotics and XOS.

Table 8. Effects of probiotics and XOS on noxious gas contents in weanling pigs ${ }^{1)}$

\begin{tabular}{|c|c|c|c|c|c|c|c|c|}
\hline \multirow{2}{*}{ Items } & \multicolumn{2}{|c|}{-Probiotics } & \multicolumn{2}{|c|}{ +Probiotics } & \multirow{2}{*}{ SEM } & \multicolumn{3}{|c|}{ p-value ${ }^{2)}$} \\
\hline & -XOS & $+\mathrm{XOS}$ & $-\mathrm{XOS}$ & $+\mathrm{XOS}$ & & Probiotics & XOS & Probiotics $\times \mathrm{XOS}$ \\
\hline $\mathrm{NH}_{3}(\mathrm{mg} / \mathrm{kg})$ & 27.4 & 21.5 & 19.3 & 18.2 & 2.3 & 0.03 & 0.04 & 0.34 \\
\hline $\mathrm{H}_{2} \mathrm{~S}(\mathrm{mg} / \mathrm{kg})$ & 4.2 & 3.4 & 4.8 & 5.8 & 1.1 & 0.15 & 0.51 & 0.40 \\
\hline
\end{tabular}

XOS, xylo-oligosaccharide; SEM, pooled standard error of the means.

1) Each mean represents 6 pens ( $n=6 /$ group).

2) Probiotics, probiotics effect; XOS, XOS effect; Probiotics $\times X O S$, interaction between probiotics and XOS. 
$[37,38]$. However, a scarcity of reports exists on the use of XOS in weanling pigs' diets. As expected, $200 \mathrm{mg} / \mathrm{kg}$ XOS improved $A D G$ and G:F in the current study, which was partly in agreement with a study, which reported that $100 \mathrm{mg} / \mathrm{kg}$ XOS increased ADG in weanling pigs without affecting G:F [13]. Due to a scarcity of available reports on the effect of $\mathrm{XOS}$ in weanling pigs, a comparison was made with other studies that used other similar functional oligosaccharides. Weanling pigs fed with MOS-supplemented diets ( $800 \mathrm{mg} / \mathrm{kg}$ ) had greater ADG and ADFI than those fed with a basal diet [29]. Furthermore, dietary supplementation of chito-oligosaccharide (COS) at 400 or $600 \mathrm{mg} / \mathrm{kg}$ promotes growth performance in weanling pigs [39]. In broilers, recent research has shown that combining probiotics (E. faecium or Lactobacillus) with prebiotics (MOS) benefited growth performance and alleviated heat stress $[14,15]$. Nevertheless, the effects of the specific combination of commercial probiotics (B. subtilis and E. faecium) and prebiotics (XOS) on weanling pig growth performance have not been studied. In this study, we failed to observe the interaction between probiotics and XOS. The combination of probiotics and XOS is worthy of further study.

The increase in ATTD of DM, N and GE during d 0-14 in response to either probiotics or XOS may mirror the improvement in growth performance. In addition, the ADFI in weanling pigs fed probiotics or XOS diets was numerically greater than those fed diet without probiotics or XOS. Accordingly, the improved ATTD and tendency towards higher ADFI in weanling pigs was supposed to explain the positive effects on growth performance in the herein study. Similarly, improved $\mathrm{N}$ and energy digestibility was also observed by previous studies in weanling pigs fed E. faecium and B. subtilis diets, respectively $[9,40]$. Because the effects of XOS on nutrient digestibility in animals have not been reported, we can only compare the results with some oligosaccharides. Supplementation of COS at $200 \mathrm{mg} / \mathrm{kg}$ increased ATTD of DM, GE, N, crude fat, Ca, and $\mathrm{P}$ in weanling pigs [41]. We speculate that positive results observed in the herein study may be due to the influence on the host health by improving the survival and establishment of live beneficial microbial dietary supplements as well as native bacteria in the gastrointestinal tract and elimination of the pathogenic ones [42]. Besides, a study found oligofructose increased the absorption surface because the short-chain fatty acid produced by microbial fermentation caused a proliferation of enterocytes and increased the number of beneficial bacteria, improved the health of the gut, decreased the intestinal $\mathrm{pH}$ value and increased the solubility of nutrients [43]. In addition, the modulation of the gut environment, improved intestinal morphology and stimulation of mucosal immune system may be responsible for the improvement in nutrient digestibility [7,44]. On the other hand, probiotics $\left(1.0 \times 10^{10}\right.$ $\mathrm{cfu} / \mathrm{kg}$ B. subtilis or $3.2 \times 10^{9}$ viable spores/g of $B$. subtilis and B. licheniformis) and prebiotics (6.8 or $13.5 \mathrm{~g} / \mathrm{kg}$ and $10 \mathrm{~g} / \mathrm{kg}$ fructooligosaccharide) had no effect on ATTD of DM or N in growing-finishing pigs $[26,27,45,46]$.

This may be attributed to the different ages of pigs, indicating that probiotics may be more effective in weanling pigs than growing-finishing pigs [47]. Further research needs to be done to explore the effects of probiotics and XOS on nutrient digestibility in weanling pigs.

Previous study demonstrated that oligosaccharides may influence the serum lipid protein profile [27]. In our study, we failed to observe an effect of probiotics and XOS on serum profiles. A study found no effect of XOS (100 to $500 \mathrm{mg} / \mathrm{kg}$ ) on Glu or TP, whereas AST, ALT, and ALP increased in weanling pigs [13]. The COS $(250 \mathrm{mg} / \mathrm{kg})$ decreased TG and TC in weanling pigs [48]. It was reported that $3,000 \mathrm{mg} / \mathrm{kg}$ probiotics and $800 \mathrm{mg} / \mathrm{kg}$ celloligosaccharides had no effect on TP or ALP in weanling pigs [49]. The lack of effect on serum profiles may be attributed to the different species as well as viability of probiotics and structure of XOS used. In addition, this could be owing to good sanitation conditions in the whole experiment so that weanling pigs were less exposed to the pathogens.

Dietary B. subtilis and E. faecium did not influence the intestinal morphology in the current study. Weanling pigs fed diets with $3 \mathrm{~g} / \mathrm{kg} \mathrm{B}$. subtilis $\left(1.4 \times 10^{11} \mathrm{cfu} / \mathrm{kg}\right)$ increased VH and VH:CD ratio [7]. Similar effects in the jejunum and ileum of weanling pigs fed diets supplemented with $3,000 \mathrm{mg} / \mathrm{kg}$ of multi microbe products containing $B$. subtilis were reported [41]. E. faecium $\left(1.0 \times 10^{8} \mathrm{cfu} / \mathrm{mL}\right)$ benefited intestinal villus [42]. Dietary supplementation of E. faecium increased $\mathrm{VH}$ and decreased CD in weaning pigs [30]. In contrast, a study failed to observe beneficial effects of probiotics on small intestinal villus [50]. The XOS increased VH:CD in jejunum in our study. Similarly, dietary supplementation with COS at 200 $\mathrm{mg} / \mathrm{kg}$ increased the $\mathrm{VH}$ and $\mathrm{VH}: \mathrm{CD}$ ratio in the jejunum and ileum in weanling pigs [41]. Some studies also did not observe any effect of MOS (1,500 or 2,000 mg/kg) on small intestinal villus $[51,52]$. To clarify these differences in the results, more research is needed to further explore the influence of probiotics and XOS on intestinal morphology in weanling pigs.

The higher activity of amylase exhibited by weanling pigs fed XOS diets was consistent with the results of a study, which observed $500 \mathrm{mg} / \mathrm{kg}$ XOS improved the activity of amylase in weanling pigs [13]. The activity of amylase may reflect the status of digestion and absorption. Furthermore, probiotics and XOS supplementation was found to increase the activity of trypsin in the present study. The improvement in the activities of trypsin and amylase may mirror the increased ATTD of DM, N, and GE in this study. The effects of probiotics or XOS on serum profiles are not well established and hence more studies are needed.

The increased lactobacilli and decreased E. coli in XOS treat- 
ments on $\mathrm{d} 14$ might mirror the better growth performance and nutrient digestibility in this study. It is well documented that microflora in the gastrointestinal tract play a key role in anatomical, physiological and immunological organ development of the host animals [53]. The inclusion of probiotics increased fecal lactobacilli and decreased E. coli in finishing pigs, which suggested that the improved intestinal microbial balance may increase the total metabolism of energy and nutrients, thus improving the conversion of feed to body mass [54]. A study observed a higher energy digestibility and greater lactobacilli count in weaning pigs fed the E. faecium supplemented diets $\left(1 \times 10^{9} \mathrm{cfu} / \mathrm{kg}\right)$ [53]. However, $3 \mathrm{~g} / \mathrm{kg}$ B. subtilis $\left(1.4 \times 10^{11} \mathrm{cfu} / \mathrm{kg}\right)$ did not affect cecal lactobacilli in weanling pigs [7]. Furthermore, the pharmacological copper level might affect lactobacilli and E. coli, which may be responsible for the lack of probiotics effect on fecal microbiota. It was reported that dietary $\mathrm{Cu}$ improved the gut health of weanling pigs [55].

Fecal $\mathrm{NH}_{3}$ emission was decreased significantly by either probiotics or XOS in the current study, which was in agreement with a previous study which reported that fecal $\mathrm{NH}_{3}$ contents were reduced by $E$. faecium administration $\left(1 \times 10^{9}\right.$ $\mathrm{cfu} / \mathrm{kg}$ ) in weanling pigs [9]. Besides, fecal $\mathrm{NH}_{3}$ was decreased in weanling pigs fed 2,000 g/kg probiotics [40]. Fecal noxious gas from feces was closely related to the feed efficiency, nutrient utilization and intestinal microbiota [56]. Therefore, the reduced fecal $\mathrm{NH}_{3}$ content was probably due to the increased $\mathrm{N}$ digestibility and lactobacilli counts. However, $\mathrm{H}_{2} \mathrm{~S}$, as most frequently reported as constituents of pig waste and were quantitatively identified as the most important sulfur-containing volatile constituents, did not differ in this study. This may be due to the lack of significant differences in both the sulfur composition and sulfur-containing amino acids of diets among the treatments [57].

According to NRC [16], the inclusion of antibiotics in diets fed to weanling pigs improved growth rate by $16.4 \%$ and feed efficiency by $6.9 \%$. Impressively, the positive effects of XOS or probiotics on the improvement in ADG and G/F in this study were comparable to the dietary inclusion of antibiotics. These findings indicated that the effectiveness of using XOS and/or probiotics obtained in the study highlighted the possibility of XOS and probiotics as the alternatives to AGP. In addition to a higher effect to promote growth, it seems that the XOS supplementation is more cost effective and easier storage than that of probiotics due to the little additional effects when the weanlings pigs fed XOS diets with probiotics.

\section{CONCLUSION}

In diets, without added antibiotics, the supplementation of XOS at $200 \mathrm{mg} / \mathrm{kg}$ or probiotics at $500 \mathrm{mg} / \mathrm{kg}$ for $28 \mathrm{~d}$ significantly increased ADG by $17 \%$ and $12 \%$, respectively, and significantly improved G/F ratio by $14 \%$ and $7 \%$, respec- tively. These benefits resulted from an improved nutrient digestibility. Furthermore, XOS supplementation increased ADFI slightly but insignificantly, trypsin and amylase activity, and fecal microbial shedding of lactobacilli, but decreased fecal E. coli counts. Besides, the supplementation of XOS or probiotics decreased fecal $\mathrm{NH}_{3}$ concentration. Once XOS is supplemented, further providing of probiotics is not needed since it exerts little additional effects.

\section{CONFLICT OF INTEREST}

We certify that there is no conflict of interest with any financial organization regarding the material discussed in the manuscript.

\section{ACKNOWLEDGMENTS}

This work was supported by the Scientific Research Fund of Sichuan Provincial Education Department (17ZA0413), the National Key Research and Development Program of China (2016YFD0500505), and Applied Basic Project of Sichuan Provincial Science and Technology Department (18YYJC0933).

\section{REFERENCES}

1. Wijtten PJA, Meulen JVD, Verstegen MWA. Intestinal barrier function and absorption in pigs after weaning: a review. $\mathrm{Br} J$ Nutr 2011;105:967-81.

2. Pie S, Lalles JP, Blazy F, et al. Weaning is associated with an upregulation of expression of inflammatory cytokines in the intestine of piglets. J Nutr 2004;134:641-7.

3. He J, Feng GD, Ao X, et al. Effects of L-glutamine on growth performance, antioxidant ability, immunity and expression of genes related to intestinal health in weanling pigs. Livest Sci 2016;189: 102-9.

4. Afrc RF. Probiotics in man and animals. J Appl Bacteriol 1989; 66:365-78.

5. Ferencik M, Mikes Z, Seman M, Ebringer L. Beneficial modification of the human intestinal microflora using orally administered enterococci. In: Proceedings of International Probiotic Conference on The Prospects of Probiotics in Prevention and Therapy of Diseases of Young; 2000. p. 46.

6. Kyriakis SC, Tsiloyiannis VK, Vlemmas J, et al. The effect of probiotic LSP 122 on the control of post-weaning diarrhoea syndrome of piglets. Res Vet Sci 1999;67:223-8.

7. Lee SH, Ingale SL, Kim JS, et al. Effects of dietary supplementation with Bacillus subtilis LS 1-2 fermentation biomass on growth performance, nutrient digestibility, cecal microbiota and intestinal morphology of weanling pig. Anim Feed Sci Technol 2014;188:102-10.

8. Wang SP, Yang LY, Tang XS, et al. Dietary supplementation with high-dose Bacillus subtilis or Lactobacillus reuteri modulates 
cellular and humoral immunities and improves performance in weaned piglets. J Food Agric Environ 2011;9:181-7.

9. Zhang ZF, Lee JM, Kim IH. Effects of Enterococcus faecium DSM 7134 on weanling pigs were influenced by dietary energy and crude protein density. Livest Sci 2014;169:106-11.

10. Wang TH, Lu S. Production of xylooligosaccharide from wheat bran by microwave assisted enzymatic hydrolysis. Food Chem 2013;138:1531-5.

11. Jain I, Kumar V, Satyanarayana T. Xylooligosaccharides: an economical prebiotic from agroresidues and their health benefits. Indian J Exp Biol 2015;53:131-42.

12. Yang J, Summanen PH, Henning SM, et al. Xylooligosaccharide supplementation alters gut bacteria in both healthy and prediabetic adults: a pilot study. Front Physiol 2015;6:216.

13. Tan BB, Ji YJ, Ding H, et al. Effects of xlyo-oligosaccharide on growth performance, diarrhea rate and plasma biochemical parameters of weaned piglets. China J Anim Nutr 2016;28: 2556-63.

14. Sohail MU, Hume ME, Byrd JA, et al. Effect of supplementation of prebiotic mannan-oligosaccharides and probiotic mixture on growth performance of broilers subjected to chronic heat stress. Poult Sci 2012;91:2235-40.

15. Mookiah S, Sieo CC, Ramasamy K, Abdullah N, Ho YW. Effects of dietary prebiotics, probiotic and synbiotics on performance, caecal bacterial populations and caecal fermentation concentrations of broiler chickens. J Sci Food Agric 2014;94:341-8.

16. National Research Council. Nutrient requirements of swine. 11th ed. Washington, DC, USA: National Academy Press; 2012.

17. AOAC International. Official methods of analysis of AOAC international. 17th ed. Gaithersburg, MD, USA: AOAC International; 2000.

18. Williams C, David DJ, lismaa O. The determination of chromic oxide in faeces samples by atomic absorption spectrophotometry. J Agric Sci 1962;59:381-5.

19. Cavell A. The colorimetric determination of phosphorus in plant materials. J Sci Food Agric 1955;6:479-80.

20. Tang M, Laarveld B, Van Kessel AG, et al. Effect of segregated early weaning on postweaning small intestinal development in pigs. J Anim Sci 1999;77:3191-200.

21. Brown DC, Maxwell CV, Erf GF, et al. The influence of different management systems and age on intestinal morphology, immune cell numbers and mucin production from goblet cells in post-weaning pigs. Vet Immunol Immunopathol. 2006;111: 187-98.

22. Nabuurs MJA, Hoogendoorn A, Van Der Molen EJ, Van Osta ALM. Villus height and crypt depth in weaned and unweaned pigs, reared under various circumstances in the Netherlands. Res Vet Sci 1993;55:78-84.

23. Jiang Z, Zheng W, Lin Y, et al. Effects of glutamine on growth performance, serum hormone levels and small intestinal mucosal enzyme activities of neonatal piglets. China J Anim Nutr 2010;22:125-31.
24. SAS Institute. SAS user's guide: statistics. Version 9.0. Cary, NC, USA: SAS Institute, Inc; 2003.

25. Alexopoulos C, Georgoulakis IE, Tzivara A, et al. Field evaluation of the efficacy of a probiotic containing Bacillus licheniformis and Bacillus subtilis spores, on the health status and performance of sows and their litters. J Anim Physiol Anim Nutr 2004;88:381-92.

26. Chen YJ, Min BJ, Cho JH, et al. Effects of dietary bacillusbased probiotic on growth performance, nutrients digestibility, blood characteristics and fecal noxious gas content in finishing pigs. Asian-Australas J Anim Sci 2006;19:587-92.

27. Wang JP, Yoo JS, Kim HJ, Lee JH, Kim IH. Nutrient digestibility, blood profiles and fecal microbiota are influenced by chitooligosaccharide supplementation of growing pigs. Livest Sci 2009;125:298-303.

28. Lojanica M, Manojlović M, Jeremić D, Petronijević S. The effects of probiotic Enterococcus faecium DSM 7134 in the weaned pigs nutrition. Biotechnol Anim Husb 2010;26:57-64.

29. Mallo JJ, Rioperez J, Honrubia P. The addition of Enterococcus faecium to diet improves piglet's intestinal microbiota and performance. Livest Sci 2010;133:176-8.

30. Zhao PY, Zhang ZF, Lan R, et al. Comparison of efficacy of lactic acid bacteria complex and Enterococcus faecium DSM 7134 in weanling pigs. J Appl Anim Res 2018;46:888-92.

31. Kritas S, Morrison R. Can probiotics substitute for subtherapeutic antibiotics? A field evaluation in a large pig nursery. In: Proceedings of the18th IPVS Congress; Hamburg, Germany; 2004.

32. Broom LJ, Miller HM, Kerr KG, Knapp JS. Effects of zinc oxide and Enterococcus faecium SF68 dietary supplementation on the performance, intestinal microbiota and immune status of weaned piglets. Res Vet Sci 2006;80:45-54.

33. Nousiainen JG, Setälä J. Lactic acid bacteria as animal probiotics. In: Salminem S, von Wright A, editors. Lactic acid bacteria. New York, NY, USA: Marcel Dekker; 1993. pp. 315-56.

34. Schweer WP, Patience JF, Schwartz K, et al. A review and evaluation of antibiotic alternatives in the literature. J Anim Sci 2017;95(Issue Suppl):48.

35. Kornegay ET, Risley CR. Nutrient digestibilities of a cornsoybean meal diet as influenced by Bacillus products fed to finishing swine. J Anim Sci 1996;74:799-805.

36. Rycroft CE, Jones MR, Gibson GR, Rastall RA. A comparative in vitro evaluation of the fermentation properties of prebiotic oligosaccharides. J Appl Microbiol 2001;91:878-87.

37. Sun ZP, Lv WT, Yu RK, et al. Effect of a straw-derived xylooligosaccharide on broiler growth performance, endocrine metabolism, and immune response. Can J Vet Res 2013;77:105-9.

38. Suo HQ, Lu L, Xu GH, et al. Effectiveness of dietary xylooligosaccharides for broilers fed a conventional corn-soybean meal diet. J Integr Agric 2015;14:2050-7.

39. Yang CM, Ferket PR, Hong QH, et al. Effect of chito-oligosaccharide on growth performance, intestinal barrier function, intestinal morphology and cecal microflora in weaned pigs. 
J Anim Sci 2012;90:2671-6.

40. Lee SJ, Shin NH, Ok JU, et al. Effects of dietary synbiotics from anaerobic microflora on growth performance, noxious gas emission and fecal pathogenic bacteria population in weaning pigs. Asian-Australas J Anim Sci 2009;22:1202-8.

41. Liu P, Piao XS, Kim SW, et al. Effects of chito-oligosaccharide supplementation on the growth performance, nutrient digestibility, intestinal morphology, and fecal shedding of Escherichia coli and Lactobacillus in weaning pigs. J Anim Sci 2008;86: 2609-18.

42. Ross GR, Gusils C, Oliszewski R, Colombo de Holgado S, González SN. Effects of probiotic administration in swine. J Biosci Bioeng 2010;109:545-9.

43. Świątkiewicz S, Koreleski J, Arczewska A. Laying performance and eggshell quality in laying hens fed diets supplemented with prebiotics and organic acids. Czech J Anim Sci 2010;55: 294-304.

44. Choi JY, Shinde PL, Ingale SL, et al. Evaluation of multi-microbe probiotics prepared by submerged liquid or solid substrate fermentation and antibiotics in weaning pigs. Livest Sci 2011; 138:144-51.

45. Houdijk JGM, Bosch MW, Verstegen MWA, Berenpas HJ. Effects of dietary oligosaccharides on the growth performance and faecal characteristics of young growing pigs. Anim Feed Sci Technol 1998;71:35-48.

46. Mountzouris KC, Xypoleas I, Kouseris I, Fegeros K. Nutrient digestibility, faecal physicochemical characteristics and bacterial glycolytic activity of growing pigs fed a diet supplemented with oligofructose or trans-galactooligosaccharides. Livest Sci 2006;105:168-75.

47. Stavric S, Kornegay ET. Microbial probiotics for pigs and poultry. In: John Wallace R, Chesson A, editors. Biotechnology in animal feeds and animal feeding. Weinheim Germany: Wiley-VCH Verlag GmbH; 2007. pp. 205-31.

48. Tang Z-R, Yin Y-L, Nyachoti CM, et al. Effect of dietary supple- mentation of chitosan and galacto-mannan-oligosaccharide on serum parameters and the insulin-like growth factor-I mRNA expression in early-weaned piglets. Domest Anim Endocrinol 2005;28:430-41.

49. Wang J, Ai PP, Diao QY, Zhang NF. Effects of compound probiotics and cell-oligosaccharide on growth performance, fecal microflora and serum parameters of weaned piglets. China J Anim Nutr 2016;28:881-90.

50. Le Bon M, Davies HE, Glynn C, et al. Influence of probiotics on gut health in the weaned pig. Livest Sci 2010;133:179-81.

51. Castillo M, Martín-Orúe SM, Taylor-Pickard JA, Pérez JF, Gasa J. Use of mannanoligosaccharides and zinc chelate as growth promoters and diarrhea preventative in weaning pigs: effects on microbiota and gut function. J Anim Sci 2008;86:94-101.

52. White LA, Newman MC, Cromwell GL, Lindemann MD. Brewers dried yeast as a source of mannan oligosaccharides for weanling pigs. J Anim Sci 2002;80:2619-28.

53. De Vrese M, Marteau PR. Probiotics and prebiotics: effects on diarrhea. J Nutr 2007;137:803S-11.

54. Meng QW, Yan L, Ao X, et al. Influence of probiotics in different energy and nutrient density diets on growth performance, nutrient digestibility, meat quality, and blood characteristics in growing-finishing pigs. J Anim Sci 2010;88:3320-6.

55. Shurson GC, Ku PK, Waxler GL, Yokoyama MT, Miller ER. Physiological relationships between microbiological status and dietary copper levels in the pig. J Anim Sci 1990;68:106171.

56. Ferket PR, van Heugten E, van Kempen TATG, Angel R. Nutritional strategies to reduce environmental emissions from non-ruminants. J Anim Sci 2002;80:168-82.

57. Ao X, Yan L, Meng QW, et al. Effects of Saururus chinensis extract supplementation on growth performance, meat quality and slurry noxious gas emission in finishing pigs. Livest Sci 2011;138:187-92. 